\title{
A JORNADA DO CONSUMIDOR: \\ A IMPORTÂNCIA DA OUVIDORIA NA GOVERNANÇA DE RELACIONAMENTO E FIDELIZAÇÃO DE CLIENTES
}

Fábio Lopes Soares ${ }^{1}$

\begin{abstract}
Resumo
Existe de certa forma uma jornada que o consumidor traça para exigir seus direitos, e a Ouvidoria se apresenta como seu mais estratégico canal de manifestação. Compreendê-la e, sobretudo, saber as consequências que ignorá-la pode trazer aos fornecedores e às partes interessadas é entender a sociedade da informação e seus impactos. Essa jornada consiste em, quando necessário, não judicializar uma reclamação ou desjudicializá-la. Entendê-la como um conjunto de canais de atendimento ou relacionamento e como as oportunidades oferecidas auxiliam na construção de uma Governança de Relacionamento, atendimento a regulamentações específicas e observância do Código de Defesa do Consumidor, além do alto nível de fidelização dos clientes.
\end{abstract}

Palavras-chave: Jornada do Consumidor. Ouvidoria. Gestão. Governança.

\begin{abstract}
There is in a way a journey that the consumer traces to demand their rights, and the Ombudsman presents himself with his most strategic channel of manifestation. Understanding it, and above all understanding the consequences that ignore it can offer to suppliers and stakeholders, is understanding the information society and its impacts. This journey consists in, when necessary, not prosecuting a claim or disqualifying it. To understand it as a set of channels of service or relationship and the opportunities offered, help in the construction of a Relationship Governance, compliance with specific regulations and the Code of Consumer Protection, in addition to the high level of customer loyalty.
\end{abstract}

Keywords: Consumer's Journey. Ombudsman. Management. Governance.

DOI:10.37814/2594-5068.2019v2.p149-158

1 PhD - Business Administration (FCU/EUA); MSc - Mestre em Direito da Sociedade da Informação (FMU); MBA - Gestão Estratégica e Econômica de Negócios (FGV); Especialista em Negociações Econômicas Internacionais (UNESCP/UNICAMP) BSc - Bacharel em Direito (FDSBC); Contabilista (ETESP); advogado, consultor e professor na FGV - Fundação Getúlio Vargas. 


\section{INTRODUÇÃO}

A forma como o consumidor/cidadão passou a interagir com os entes públicos ou empresas da iniciativa privada, tanto no uso de serviços públicos como no uso ou aquisição de produtos/serviços, foi alterada à medida que a denominada Sociedade da Informação ocorreu.

No Brasil, dessa interação, sobretudo após 1994 com a distribuição e acesso à internet e após 2007 com políticas de acesso ao crédito, construíram-se novos paradigmas e escalas de consumo nunca registradas.

A defesa dos interesses dos consumidores e cidadãos teve um importante aliado: um componente organizacional chamado Ouvidoria, capaz de registrar e representar a voz do cliente dentro das organizações, assim como gerir com a devida governança e representação a fim de garantir a harmonia nas relações entre fornecedores e consumidores.

Essa governança não somente reduz riscos, como propõe mudanças no comportamento de seus atores, transformando Ouvidorias em instrumentos de gestão e representação plenos, com o uso de modernas técnicas de mensuração de intangíveis e garantia de direitos individuais.

Compreender a jornada pela defesa e manifestação de direitos e necessidades, ao longo do consumo de produtos e serviços públicos ou privados representados por essa Ouvidoria moderna e com modelo único no mundo, é o estudo deste artigo que consagra a compilação de ideias sobre o tema.

\section{A JORNADA DO CONSUMIDOR}

Sabe-se que consumidores detêm direitos e deveres. Contudo, a harmonia de suas relações ocorre também pela plena compreensão dos direitos e deveres do fornecedor, tanto da iniciativa privada como do poder público.

Quando os direitos de um consumidor passam a ser desrespeitados, inicia-se uma trajetória, algumas vezes de forma frustrada, pela busca da defesa dos direitos lesados: a essa trajetória denominamos Jornada do Consumidor.

Essa Jornada passa por registrar, nos canais disponíveis para sua manifestação, a mediação necessária, nem sempre restaurativa do conflito, mas ao menos conciliadora ou mitigadora do problema.

O gestor dessa Jornada passa a ser a Ouvidoria, tanto pelo seu aspecto estratégico como, para alguns setores da economia e do poder público, por seu caráter regulatório.

Se compreendermos que cada canal viável que o consumidor detém para reclamar possibilita que a empresa ouça essa voz, a soma desses canais oferece mecanismos de melhor relacionamento, tanto pela solução pontual como pela função mais nobre do aspecto gestor da Ouvidoria: a solução de demandas coletivas ou de volumes de manifestações através de sistemas complexos de resolução de conflitos e de análise de causas raiz.

Métodos cada vez mais modernos e testados são apresentados para compreensão dessa Jornada. É o caso da TCNR - Teoria do Custo da Não Reclamação, em que sistemas jurimétricos de análise de causa raiz são capazes de compor modelos de Governança de Relacionamento. 
De certa forma podemos compreender que, quanto mais próximo da judicialização o consumidor chega, mais caro para o poder público ou iniciativa privada a manifestação se apresenta.

Essa Jornada pode ainda ser classificada em "Não Judicializada" ou "Judicializada", possibilitando às Ouvidorias formas de mensurar seus custos e melhor atuar preventivamente, inclusive em canais internos e externos, tendo por diretriz soluções definitivas. Sua formatação pode assim ser apresentada:

\section{FIGURA 1 - A Jornada do Consumidor (Governança de Relacionamento de uso da TCNR)}

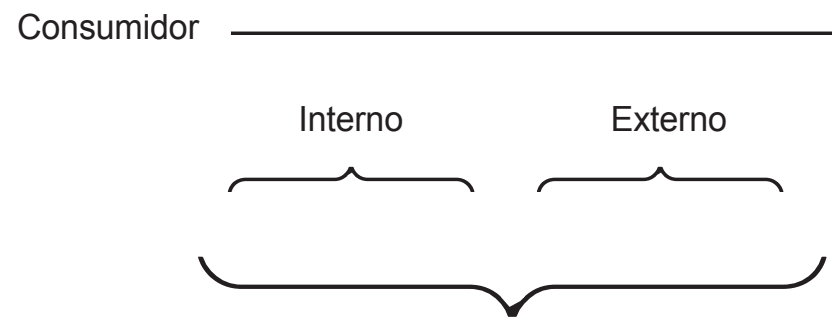

Não Judicialização

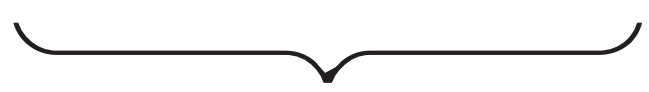

Judicialização

Mas quem são essas áreas denominadas Ouvidorias e como ao longo do tempo seu modelo influenciou um relacionamento tão estratégico e com propostas capazes de fazer com que áreas então entendidas como de custo passassem a se tornar centros de resultados?

\section{OUVIDORIA PÚBLICA E OUVIDORIA PRIVADA}

O modelo brasileiro de Ouvidoria ocorreu inicialmente com o aproveitamento de todo o histórico de defesa dos interesses dos usuários do serviço público que, posteriormente, culminou na obrigatoriedade dos bancos em implantar Ouvidorias, mediante a publicação da resolução 3477/07 do Banco Central do Brasil - Bacen e da Lei 13.460/17, conhecida como Código de Defesa do Usuário de Serviço Público.

No caso da norma do Bacen - revogada por conta da publicação da Resolução 3849/10 e posteriormente pela Resolução 4.433/2015, necessárias para a atualização de sua função com os bancos -, ela iniciou historicamente, e de forma coercitiva, o aperfeiçoamento das Ouvidorias no Brasil para a iniciativa privada. 
Esse aperfeiçoamento ocorreu, de um lado, com a iniciativa privada na implantação das Ouvidorias mediante o uso de sistemas gerenciais avançados e, por outro, com o poder público adotando as práticas da iniciativa privada. Toda essa mudança ocorrendo em meio a alterações econômicas e legais, com um Brasil em pleno desenvolvimento econômico.

A construção, o conceito e as bases da Ouvidoria Brasileira também têm seu lastro na formação da $\mathrm{ABO}$ com a implantação das primeiras Ouvidorias no Brasil, com sua própria fundação em 1995 e a consolidação nos diversos Encontros e Congressos Nacionais realizados com o objetivo, entre outros, de aperfeiçoar o instituto da Ouvidoria. Por consequência, chegou-se ao Código de Ética da ABO em 1997 e a vários marcos legais reguladores sobre o tema.

Temos assim que Ouvidoria é:

Um componente organizacional da empresa voltado para ser um interlocutor entre os consumidores e a instituição. Trata sobre as manifestações dos cidadãos, registradas sob a forma de reclamações, denúncias, sugestões, críticas ou elogios. (GUIA DE OUVIDORIAS)

De certa forma, esse componente organizacional ofereceu condições de constituir a missão de uma Ouvidoria no Brasil, qual seja: Ouvidoria é a instituição que representa os legítimos interesses dos cidadãos no ambiente em que atua, na busca de soluções definitivas.

Nesse esforço comum, foi também construída a definição dos objetivos da Ouvidoria, que passaria a não contar mais apenas com pessoas em sua gestão, mas que deveria ser pautada em processos gerenciais, organizados de tal forma que, na ausência de um Ouvidor, suas tarefas e missão gerassem perenidade ao componente organizacional.

O objetivo principal da Ouvidoria, então, doravante é:

Ser uma atividade institucional de representação autônoma e independente, de caráter conciliatório, pedagógico, instrumental e estratégico, que acolhe as manifestações dos cidadãos, analisa e fornece informações aos gestores, visando à promoção da melhoria contínua e a busca de soluções efetivas.

Por essas razões e com olhar histórico, uma Ouvidoria deve ser reconhecida por ser a mais pura representação da voz do cidadão na organização, direcionando ações de melhorias, fidelizando clientes, gerando o valor que antes era obtido em pequenas interações com a organização, pautando-se em processos gerenciais e uma ética de convivência capaz de harmonizar as relações, contribuindo para a melhoria de produtos e serviços, tanto da iniciativa privada como no poder público.

A Ouvidoria passou a ser em países como o Brasil um componente organizacional específico para gestão das manifestações dos consumidores e cidadãos, o que também lhe ofereceu condições de gerenciar as informações relativas aos ativos intangíveis ligados a reclamações.

Uma Ouvidoria aliada às áreas estratégicas de relacionamento com clientes tem a função de salvaguardar ativos intangíveis, ao lado das controladorias financeiras tradicionais, com foco na prevenção e otimização de processos, produtos e serviços, servindo tanto o consumidor quanto a empresa/órgão público. 


\section{OUVIDORIA COMO INSTRUMENTO DE GESTÃO}

Apesar de muito já ter sido estudado e escrito a respeito das Ouvidorias, observa-se que, por conta da atual conjuntura econômica e de problemas de controles internos, a questão atendimento fez com que o relacionamento com clientes em todas as suas fases - antes, durante e depois - fosse entendido como diferencial estratégico.

A constatação de que o relacionamento com clientes se transformou em commodity para as empresas é fruto da livre concorrência e da adequação das empresas ao Código de Defesa do Consumidor e ao recente Código do Usuário de Serviços Públicos. Porque, ao estabelecerem as regras para o correto equilíbrio entre os consumidores e quaisquer fornecedores de serviços e produtos, eles determinaram os direitos e deveres de ambas as partes, exigindo das empresas diferenciais que viabilizassem seus negócios e oferecessem crescimento sustentável.

Algumas empresas demonstram o diferencial estratégico de serviços de relacionamento capazes de superar as expectativas dos consumidores, garantindo assim sua justa fidelização, contudo os rankings de reclamações, a perda de base de clientes e, sobretudo, os índices de judicialização têm demonstrado o desafio no que se entende, atualmente, como relacionamento.

As empresas não suportam mais simplesmente atender ou demonstrar ações de marketing sobre marcas que ainda desrespeitam o cliente: o consumidor moderno quer interagir, dialogar e exige valor agregado. Em verdade, a integração do cliente não denota mais função estratégica, mas sim uma questão de sobrevivência do negócio.

Uma Ouvidoria por excelência deve ser a mais pura representação da voz do cliente na empresa, cuja subordinação deve estar diretamente ligada ao presidente da empresa, autoridade máxima, ou ao conselho executivo.

Essa voz, que interage e não mais reclama em um SAC, direciona as ações de melhoria, fideliza novos clientes e gera o valor que antes era obtido em pequenas interações com a empresa.

Essa voz se faz representar na figura dos Ouvidores que não podem ser tidos como simples canal de atendimento, mas sim como diferencial estratégico em forma de componente organizacional. A Ouvidoria deve ser assumida como parte da empresa, capaz de recomendar e redirecionar o rumo das decisões, acompanhadas das necessidades, dos valores, da imparcialidade, da legalidade e da conduta ética, atributos dessa nova entidade corporativa.

Uma Ouvidoria deve ser independente, fruto da evolução dos valores internos e consequência da correta integração com o cliente, cujo resultado final é a garantia da perenidade da empresa, do crescimento de seus negócios, capaz de alterar processos e gerenciar estratégias comerciais: ela passou a representar sistemas mais complexos de cadeias de valor no tempo para que, com isso, se tornem centros de resultado e inovação.

\section{GOVERNANÇA DE RELACIONAMENTO}

Para que se possa propor instrumento capaz de gerar Governança de relacionamento, devemos utilizar métodos que mensurem as reclamações de consumidores em base de dados tal capaz 
de gerar soluções individuais que respeitem o consumidor e a coletividade. As consequências podem ser as políticas públicas amparadas na jurimetria, que determinam previamente algum sistema de Governança de Relacionamento.

Para se entender Governança de Relacionamento, antes precisamos compreender o uso da conhecida Governança Corporativa. O termo Governança Corporativa foi criado no início da década de 1990 nos países desenvolvidos para definir as regras que regem o relacionamento, dentro de uma companhia, dos interesses de acionistas controladores, acionistas minoritários e administradores.

No Brasil, o Instituto Brasileiro de Governança Corporativa - IBGC apresenta a seguinte definição para Governança Corporativa, que é utilizada na B3 - Brasil, Bolsa, Balcão:

Governança Corporativa é o sistema pelo qual as organizações são dirigidas, monitoradas e incentivadas, envolvendo os relacionamentos entre proprietários, conselho de administração, diretoria e órgãos de controle. As boas práticas de governança corporativa convertem princípios em recomendações objetivas, alinhando interesses com a finalidade de preservar e otimizar o valor da organização, facilitando seu acesso ao capital e contribuindo para a sua longevidade.

O conceito de governança corporativa pela ótica da maximização da riqueza dos acionistas como principal responsabilidade dos executivos contraria o chamado modelo de equilíbrio dos interesses dos stakeholders.

Esse sistema somente nasceu após desequilíbrios econômicos mundiais que determinaram a convenção de sistemas de controle interno capazes de reduzir riscos sistêmicos. Contudo, fortaleceu a possibilidade de empresas com outras constituições societárias, dentro do ordenamento jurídico brasileiro, a gerarem melhores índices de liquidez e, com isso, oferecer eficiência operacional, garantindo a manutenção de sua função social.

Uma vez constituídos, os fundamentos de estratégia societária e contratual das empresas, seus atos constitutivos e a redução de riscos justificam a criação de sistemas de Governança Corporativa. Resta a análise de Governança Cidadã, que compreende também a Governança de Relacionamento.

O cidadão passou a esperar do poder público a administração da boa res publica, enquanto o consumidor vinculado exclusivamente à iniciativa privada tem a expectativa da realização da legalidade e da boa-fé contratual que pode, por exemplo, ser materializada na entrega de produtos e serviços com qualidade.

A ausência de sistemas de Governança de Relacionamento pode até mesmo levar à busca do cidadão pelo Poder Judiciário, sobretudo em questões ligadas a pedidos de indenização por conta de desrespeito aos seus direitos básicos.

Segundo o CNJ, em seu relatório Justiça em Números publicado em 2017/2018, houve um aumento das ações judiciais relativas a demandas de consumo não somente em números absolutos, mas, principalmente, quanto à sua natureza, conforme se verifica: 


\section{GRÁFICO 1 - Assuntos mais demandados no Poder Judiciário}

1. DIREITO DO TRABALHO - Rescisão do Contrato de Trabalho/Verbas Rescisórias

2. DIREITO CIVIL - Obrigações/Espécies de Contratos

3. DIREITO TRIBUTÁRIO - Dívida Ativa

4. DIREITO DO CONSUMIDOR - Responsabilidade do Fornecedor/Indenização por Dano Moral

5. DIREITO CIVIL - Responsabilidade Civil/Indenização por Dano Moral
$4.980 .359(11,75 \%)$

$1.953 .651(4,61 \%)$

$1.737 .606(4,10 \%)$

$1.667 .654(3,94 \%)$

$903.628(2,13 \%)$

Quando observamos as ações mais demandadas nos recursos judiciais, aquelas ligadas a Relacionamento com Consumidores (Direito do Consumidor) se destacam:

\section{GRÁFICO 2 - Assuntos mais demandados nas turmas recursais}

1. DIREITO DO CONSUMIDOR - Responsabilidade do Fornecedor/Indenização por Dano Moral

2. DIREITO CIVIL - Responsabilidade Civil/Indenização por Dano Moral

3. DIREITO CIVIL - Obrigações/Espécies de Contratos
$144.499(12,98 \%)$

$71.637(6,43 \%)$

$62.298(5,59 \%)$

Enquanto no Poder Executivo as reclamações aumentam e geram maior intervenção, multas e sobretudo maior poder de tomada de consciência, com o consequente boicote e troca de fornecedores, no Poder Judiciário as questões relativas à Responsabilidade Civil ligadas ao Fato do Produto passaram a ser julgadas aumentando o contingenciamento das empresas e determinando que o relacionamento com o cliente deve ser, mais do que nunca, estratégico para os negócios.

Um sistema de Governança de Relacionamento e Cidadã determina então um nível de relacionamento entre as partes interessadas que resulte em um comportamento ético e solidariamente responsável pela cadeia de valor.

Em outras palavras, a criação de um sistema de accountability pautado em práticas e séries históricas de registro de manifestação garante melhores práticas de comportamento tanto para empresas públicas como para a iniciativa privada. 
No extremo, podemos propor, com base no sistema de Governança Corporativa tradicional, a seguinte definição para Governança Cidadã, originalmente desenvolvida e lecionada por Edson VISMONA (SOARES, 2016):

\begin{abstract}
Governança Cidadã é o sistema pelo qual as organizações do poder público e da iniciativa privada são dirigidas, monitoradas e incentivadas, envolvendo os relacionamentos entre gestores públicos, proprietários, conselho de administração, diretoria, órgãos de controle e consumidores. As boas práticas de Governança Cidadã convertem princípios em recomendações objetivas, alinhando interesses com a finalidade de preservar e otimizar o valor da organização e a boa res publica pautada na ética, transparência e contribuindo para a sua longevidade e realização da função social da empresa.
\end{abstract}

Esse sistema também oferece os limites externos de aceitação de reclamações para consumidores e cidadãos, na medida em que o modelo de negócios de empresas internalizado pela denominada Sociedade da Informação não aceita mais excessos por falta de qualidade ou qualquer tipo de prática abusiva, gerando manifestações a todo e qualquer tipo de canal de atendimento, o que se reflete nos ativos das empresas.

A Governança de Relacionamento passa a ser uma mescla entre Governança Corporativa e Cidadã aplicada didaticamente como meio de harmonia nas relações de consumo, respeitado o direito individual previsto na Constituição Federal e capaz de determinar o limite do risco empresarial, aqui apresentado como a melhor compreensão da Harmonia das Relações de Consumo perante a Sociedade da Informação.

\title{
6 DESAFIOS DA OUVIDORIA MODERNA
}

À medida que percebemos um ajuste nos controles para tratamento de demandas individuais, constatamos que a dificuldade de gestão aumentou no que diz respeito ao tratamento das demandas coletivas e que ela prejudica diretamente os ativos intangíveis de empresas e órgãos públicos.

Dentro dessa breve Jornada do Consumidor, a Desjudicialização iniciada pela Enajud (Estratégia Nacional de Não Judicialização) se faz mais do que importante e essencial.

Se faz necessária uma relação de consumo pautada na Não Judicialização, capaz de oferecer canais e meios de solução que afastem do Judiciário demandas simples, cujo respeito ao consumidor e empática demonstração de confiança e boa-fé reduziriam o custo para fornecedores e sobretudo fariam uso de orçamento público de forma adequada.

Entender que a prática e a construção de políticas no relacionamento com clientes e cidadãos devem ser em sentido vertical e não horizontal, capazes de construir uma jornada profunda de mudança cultural aliada a estudos jurimétricos e, sobretudo, de empatia, tanto na ética da convivência como no olhar maduro e presente do coletivo, priorizando a Não Judicialização, garante o direito básico à tutela jurisdicional quando as tentativas de superar a falta da harmonia na relação entre as partes forem esgotadas. A tutela jurisdicional é um direito constitucional, portanto a apreciação pelo Poder Judiciário não pode ser afastada ou garantida pela gestão do relacionamento.

156 | Revista Científica da Associação Brasileira de Ouvidores/Ombudsman - Ano 2 - nº 2 - 2019 
A ausência de capacitação das equipes para áreas de Ouvidoria, o controle precário de demandas ou de relatórios que determinem a causa raiz dos problemas e sobretudo a necessidade de um programa de MCQ - Melhoria Contínua de Qualidade que promova a mudança de comportamento, gerando uma legítima Cultura de Servir, reforçam os desafios para as modernas Ouvidorias.

A Governança de Relacionamento deve empreender esforços para garantir harmonia para ambas as partes dessa relação, sem prejuízo aos direitos individuais, mas promovendo a livre concorrência prevista na Constituição Federal e nas melhores práticas de sustentabilidade hoje difundidas no mundo.

\section{CONCLUSÃO}

Em decorrência da Sociedade da Informação, a forma como os consumidores e cidadãos passaram a se manifestar perante os órgãos públicos e empresas da iniciativa privada gera um desafio para qualquer executivo ou gestor de Ouvidorias ou áreas de relacionamento com clientes.

Essa forma denominada de Jornada do Consumidor exige a criação e controle de uma importante Governança de Relacionamento, condicionada não somente ao respeito de direitos e deveres, mas também ao uso de instrumentos da moderna administração para melhoria de produtos, serviços e a correta democratização dos meios de manifestação.

De todas as áreas de relacionamento, a Ouvidoria mostra-se, no Brasil, como a gestora e sponsor desse processo: tanto por conta de sua condição de componente organizacional e de independência, como por sua capacidade de oferecer melhoria contínua nas demandas coletivas e nos motivos mais reclamados.

Essa Jornada alia sistemas de controle modernos como a Jurimetria, sistemas maduros de cálculo de custo de reclamações e conduz à perenidade de marcas, integrando a voz do cliente aos limites legais e ajustando necessidades entre fornecedores e consumidores.

Por essas razões, uma nova onda de uso das Ouvidorias se apresenta: uma onda de justa representação cidadã e de consumidores mais conscientes, a qual reconhece e apresenta uma Ouvidoria amparada em processos robustos, com vocação para a solução de causa raiz de novos desafios, para a construção de modelos perenes de Governança e influenciadora de um olhar mais empático e regulador dirigido ao relacionamento entre o cidadão/consumidor e o poder público/fornecedor.

\section{REFERÊNCIAS}

BALMAN, Zygmunt. Vida para consumo. São Paulo: Zahar, 2007. Vida em fragmentos: sobre a ética pós-moderna. São Paulo: Zahar, 2011.

BARLOW, J; MOLLER, C. Reclamação de cliente, não tem melhor presente. São Paulo: Futura, 1996.

BENJAMIN, Antonio Herman. Manual de Direito do Consumidor. 5. ed. São Paulo: Revista dos Tribunais, 2013. 
CASTELLS, Manuel. A era da informação: economia, sociedade e cultura. In: A sociedade em rede. São Paulo: Paz e Terra, 2000.

DUPAS, Gilberto. Ética e poder na Sociedade da Informação. 3. ed. São Paulo: Editora Unesp, 2000.

GOMES, Josir Simeone; SALA, Joan M. Amat. Controle de gestão: Uma abordagem contextual e organizacional. 3. ed. São Paulo: Editora Atlas, 2001.

GUIA DE OUVIDORIAS BRASIL. São Paulo: Padrão Editorial, 2011.

IBGC. Disponível em: www.ibgc.com.br. Acesso em: 2 jun. 2017.

MORAIS, Alexandre de. Direito Constitucional. 23. ed. São Paulo: Editora Atlas, 2008.

NOLAN, Thomas W. et al. The Improvement Guide. EUA: Jossey-Bass, 1996.

PAESANI, Liliana Minardi (Org.). O Direito na Sociedade da Informação. São Paulo: Atlas, 2007.

SOARES, Fábio Lopes. A ética necessária às empresas na era da Sociedade da Informação. RBMAD - Revista Brasileira de Meio Ambiente Digital e Sociedade da Informação, São Paulo, 2014.

Governança Cidadã: Alternativa para garantia da realização da função social das empresas e de sustentabilidade econômica. Revista da Faculdade de Direito de São Bernardo do Campo, São Bernando do Campo, v. 22, jan./jun. 2016 v. 103, 2016

Jurimetria e Sociedade da Informação: o custo das reclamações nas relações de Consumo, Brasília: RDC,

TAKAHASHI, Tadao (Org.). Sociedade da Informação no Brasil: livro verde. Brasília: Ministério da Ciência e Tecnologia, 2000.

VISMONA, Edson Luiz; BARREIRO, Adriana Eugenia Alvim. Ouvidoria brasileira: o cidadão e as instituições. Campinas: Editora Unicamp, 2015. 